\section{SÔBRE A LEI RHODIA "DE JACTU”}

(Tradução do Livro XIV, N. ${ }^{\circ}$ 2, do Digesto).

\section{Contribuição ao Congresso Jurídico de Pôrto Aleǵre}

Apresentado por

\section{Alexandre Augusto de Castro Corrêa}

Bacharel pela Faculdade de Direito de São Paulo.

\section{1 - PAULO, no livro segundo das "SENTENGAS"}

A LEI RHODIA dispõe que fazendo-se o alijamento de mercadorias para salvar o navio, deve ser ressarcido pela contribuição de todos o que se sacrificou em benefício de todos.

2 - O MESMO, no livro trigésimo-quarto ao EDITO.

$\mathrm{Se}$, periclitando o navio, se fizer o alijamento, os donos das mercadorias perdidas, que tiverem feito um contrato de transporte, devem agir contra o capitão do navio "ex locato", êste, por sua vez, pode agir "ex conducto" contra os demais afretadores, cujas mercadorias se salvaram, a fim de que o prejuízo se distribua proporcionalmente. SÉRVIO diz mesmo que se deve agir "ex locato" contra o capitão do navio de forma que êste retenha as mercadorias dos outros afretadores até êles contribuírem com sua parte na avaria; e declara, ainda, que mesmo sem reter as mercadorias o capitão deve, além disso, agir "ex locato" contra os afretadores: pois, que sucederá, havendo passageiros sem mercadorias? evidentemente, existindo mercadorias, é mais útil retê-las. Mas, não tendo alugado o navio inteiro, agirá "ex conducto", como os passageiros que locaram um lugar no navio: pois é altamente equitativo comunicar o prejuízo àqueles que, graças ao sacrifício de mercadorias alheias, conseguiram salvar as suas próprias.

1 - Se, conservadas as fazendas, o navio se danificar ou se alguma coisa fôr desarmada, não haverá contribuição, por ser a natureza das coisas dispersadas a bem do navio, diferente da natureza daquelas pelas quais alguém recebe uma retribuição; pois, se um ferreiro quebrar sua bigorna ou martelo, tal prejuízo não será imputado ao locatário de seus serviços. Verificando-se, porém, o prejuízo por vontade dos afretadores ou por temor dalgum perigo, haverá contri- buição. 2 - Tendo vários comerciantes reunido, no mesmo navio, mercadorias de espécies diversas, viajando, no mesmo navio, vários passageiros, escravos e homens livres e tornando-se necessário lançar mercadorias ao mar, por causa de borrasca, perguntou-se: devem todos os afretadores contribuir pelo ressarcimento das fazendas alijadas, mesmo os que tenham confiado efeitos tais como pérolas, que não sobrecarregam o navio? que quota deve ser prestada? deve-se também contribuir pela perda de homens livres? qual a ação competente para resolver o caso? Decidiu-se no sentido da contribuição por parte de todos os interessados no alijamento, porque as coisas salvas devem êste tributo: por conseguinte, até o proprietário do navio fica obrigado a uma quota; a importância do alijamento deve ser distribuída segundo o preço das mercadorias; quanto aos homenslivres, é impossível estimar-lhes o valor (grifo nosso); os proprietários das fazendas sacrificadas devem agir "ex conducto" contra o marinheiro, isto é, o capitão do navio. Discutiu-se, igualmente, se devem ser avaliadas as vestes e os anéis dos passageiros; e todos decidiram pela afirmativa, excetuando as coisas carregadas para o consumo a bordo, como os víveres: tanto mais quanto cada passageiro, no momento de alijar as mercadorias, tinha pôsto em comum os víveres que trouxera. 3 - Resgatado o navio do ataque de piratas, SÉRVIO, OFÍLIO e LABEÃO afirmam que todos os afretadores devem contribuir para o resgate: as coisas, porém, roubadas pelos piratas a um ou a alguns dentre os afretadores redundam em prejuízo dêstes, não devendo o prejuízo ser indenizado pelos que tiverem salvo suas mercadorias. $4-\mathrm{A}$ contribuição será prestada avaliando-se as coisas salvas e perdidas, pouco importando que as últimas possam alcançar valor superior ao do custo, pois a indenização é dos prejuízos e não dos lucros; porém, quanto às mercadorias que devem contribuir para a indenização, o valor destas será estimado não pelo seu custo, mas pelo preço de venda que alcançarem. 5 - Não se avaliarão os escravos mortos por afogamento, pela mesma razão em virtude da qual não se avaliam os mortos a bordo, nem os que se precipitam ao mar. 6 - Havendo afretadores insolváveis, o prejuízo não será imputado ao capitão do navio, que não é obrigado a examinar a situação econômica de cada cliente. 7 - Se as mercadorias alijadas se recuperarem, não há contribuição: assim, já tendo sido prestada, os que a tiverem efetuado agem contra o capitão "ex locato" de modo que êste exerça a ação "ex conducto" e restitua o que tiver exigido. 8 - A mercadoria alijada continua propriedade de seu dono, não se tornando do apreensor, pois não se reputa coisa abandonada. 3 - PAPINIANO, no livro décimo-nono dos "PARECERES".

Haverá contribuição se um mastro ou outro aparelho do navio fôr cortado para remover perigo comum. 


$$
-54-
$$

4 - CALLISTRATO, no segundo livro das "CONSULTAS".

$\mathrm{Se}$, a fim de aliviar um navio sobrecarregado, que não poderia entrar com sua carga em pôrto fluvial ou marítimo se fêz o transporte em chalupa de algumas fazendas, a fim de que a embarcação não viesse a periclitar fora do rio ou no próprio pôrto fluvial ou marítimo e se a chalupa submergir, haverá rateio entre os que salvaram suas mercadorias no navio, em favor dos que perderam as suas na chalupa, como se tivesse havido alijamento; é o que também SABINO prova no segundo livro de pareceres. Pelo contrário, salvando-se a chalupa, com parte do carregamento e naufragando o navio, não há contribuição dos que perderam suas fazendas no navio, porque só se exige o rateio do alijamento, salvando-se o navio. - 1 . Mas, se a nave (que durante uma tempestade se salvou pelo alijamento das mercadorias dum só afretador) veio a naufragar alhures, e as fazendas dos outros se recuperaram pelo trabalho remunerado de mergulhadores, SABINO responde igualmente que o rateio deve ser feito em benefício daquele cujas mercadorias se alijaram para salvar o navio, entre os que salvaram suas mercadorias mediante o trabalho de mergulhadores. Porém, as fazendas pertencentes aos que assim as salvaram, não devem contribuir em benefício do que alijou suas fazendas durante a viagem, no caso de algumas se terem salvo pelo trabalho de mergulhadores; pois, as fazendas daqueles afretadores não se podem considerar alijadas a bem do navio que naufragou. 2 - Havendo, entretanto, alijamento e deteriorando-se as fazendas conservadas a bordo, pertencentes a um afretador, surge a questão de saber se êle deve ser obrigado a contribuir, pois não se deve onerá-lo com o duplo prejuízo da contribuição e do deperecimento de suas mercadorias; deve, porém, sustentar-se que êle é obrigado a contribuir de àcốrdo com o preço atual das fazendas: assim, valendo as mercadorias de dois afretadores vinte cada uma, e caindo a dez, por causa da umidade, o valor das pertencentes a um dêles, aquêle, cujas fazendas se conservaram intatas, contribuirá pelo valor de vinte e o outro contribuirá por dez; tal opinião pode ser sustentada mesmo distinguindo-se as causas da deterioração, isto é, mesmo indagando-se se o dano seguiu à descobertura das fazendas, determinada pelo alijamento ou se resultou do fato de se acharem as mercadorias arrumadas em outro lugar em ângulo diverso, exposto à penetração das ondas; haverá, nesta hipótese, contribuição; no primeiro easo, ficará o afretador isento da contribuição, porque o alijamento o prejudicou? em segundo lugar, não se deterioraram porventura as coisas, em virtude da umidade, causada pelo alijamento? Deve, porém, empregar-se uma distinção mais precisa, visando conhecer qual o prejuízo maior, - causado pelo dano ou o proveniente da contribuição: se as fazendas valiam, por exemplo, vinte e o montante da contribuição é dez, sen- do dois o valor dos prejuízos, o afretador, deduzindo a importância de dois, representada pelo prejuízo, deve contribuir pelo restante; qual será pois a solução, quando o prejuízo fôr maior do que a contribuição? quando, por exemplo, as fazendas tenham sofrido uma depreciação avaliada em 10 moedas de ouro, sendo de dois o montante da contribuição? evidentemente o afretador não deverá arcar com ambos os prejuízos; vejamos, porém, se também êle deve contribuir: pois, que devo preferir: perder as mercadorias alijadas ou conserválas deterioradas, por causa da descobertura? assim como se indeniza ao que perdeu, deve-se também indenizar aquêle que sofreu uma depreciação em suas mercadorias por causa do alijamento. Assim responde PAPÍRIO FRONTO a esta consulta.

5 - HERMOGENIANO, no segundo livro do Epítome Jurídico.

O prejuízo resultante da perda do navio não é ressarcido pela contribuição comum entre os que salvaram suas fazendas do naufrágio pois só se admite a distribuição comum do prejuízo quando o alijamento tiver parecido aconselhável em benefício das outras fazendas em perigo comum, salvando-se o navio. $1-$ Haverá contribuição por igual quando se cortar um mastro para salvar as mercadorias do navio.

\section{6 - JULIANO, no octogésimo-sexto livro do Digesto.}

Um navio, avariado por causa de tempestade, tendo seus armamentos mastro e antenas queimados por raio, foi levado a Hippona $e$, aí, consertados no momento e às pressas os armamentos, rumou para Ostia, transportando intata a carga; perguntou-se se os proprietários da carga deviam ressarcir ao capitão o dano sofrido? A resposta é negativa: pois o capitão fêz as despesas mais para consertar o navio do que no interêsse das mercadorias. FENO.

7 - PAULO, no terceiro livro do epítome do Digesto de AL-

Avariado o navio ou naufragado, aquilo que cada um conseguir salvar PAULO diz que pertence. ao que salvou, assim como sucede relativamente às coisas salv̀as dum incêndio.

\section{8 - JULIANO, no segundo livro a MINICIO.}

Os que fazem o alijamento para salvar o navio, não têm a intenção de abandonar as coisas alijadas; com efeito se vierem a encontrálas, levá-las-hão consigo, e se suspeitarem do lugar onde foram alija. das, para aí irão procurá-las: as fazendas alijadas serão havidas como a coisa que alguém, cansado, depõe um momento na rua, para vir, logo em seguida, levantá-la, ajudado por outros. 
9 - VOLÚSIO MECIANO, no comentário à lei RHODIA.

Petição de EUDEMO NICOMEDENSE ao imperador ANTONINO.

Imperador D. ANTONINO, tendo nós naufragado na ITÁLIA (em ICÁRIA), fomos saqueados pelos publicanos, habitantes das ilhas CICLADAS. ANTONINO disse a EUDEMO: Eu, senhor do orbe terrestre e legislador do mar. Instaure-se o processo segundo a lei RHODIA, sôbre o direito marítimo, na medida em que nenhuma de nossas leis lhe fôr contrária. Assim também decidiu o imperador AUGUSTO. PAULO.

10 - LABEÃO, no primeiro livro dos "CASOS", resumidos por

Se fizeste um contrato de transporte de escravos, não tens o direito de reclamar o preço do transporte, na hipótese de um dêles morrer a bordo. PAULO: Deve-se indagar o que foi ajustado, se o preço que se devia pagar pela carga ou pelo transporte; não sendo possível verificá-lo bastará ao capitão provar que o contrato foi de carga do escravo.

1 - Se alugaste o navio com a condição dêle transportar tuas mercadorias e o capitão, sem necessidade, as transportou em navio pior, sabendo que era contra tua vontade e se tuas fazendas desapareceram com o navio em que afinal foram transportadas, tens contra o primeiro capitão a ação "ex locato conducto". PAULO - A solução é contrária se durante a viagem os dois navios naufragaram sem dolo ou culpa de ambos os capitães. O mesmo direito se aplicará quando o primeiro capitão, detido pùblicamente, fôr proibido de navegar com tuas mercadorias e também quando realiza contigo um contrato de transporte, sujeitando-se a uma penalidade em teu favor se antes de certo dia não desembarcar tuas mercadorias no lugar determinado pelo contrato e não tiver culpa de esperar que a pena lhe seja abonada; na mesma ordem de idéias, adotaremos solução idêntica provado que o capitão, impedido por doença, não pôde nuavegar e ainda se o navio sofrer avaria sem dolo nem culpa de sua parte. 2 - Se fizeste um contrato de transporte, obrigando-te a transportar duas mil ânforas e depois transportares ânforas, deves o preço de duas mil ânforas. PAULO - Ainda, alugando-se o navio segundo o pêso das mercadorias, o preço devido é o correspondente a dois mil; se o -preço contratado fôr por número de ânforas carregadas, a solução é contrária: com efeito, deves o preço de tantas ânforas quantas as mencionadas no contrato de transporte.

\section{RELATÓRIO E PARECER}

Relator: ELPÍDIO FERREIRA PAES

O dr. Alexandre Augusto de Castro Correia, com alto propósito de colaborar no Congresso Jurídico, que ora se realiza, em comemoração ao cinqüentenário desta Faculdade, enviou uma tradução do título II do Livro XIV do Digesto, que versa a famosa LEX RHODIA DE IACTU. Limitou-se o autor a traduzir o texto latino, procurando, entretanto, acompanhar, de perferência, o verdadeiro pensamento dos juristas romanos que redigiram o comentário daquele velho diploma legal, do que a servil literalidade, que nem sempre reproduz perfeitamente o sentido do original. $\mathrm{O}$ trabalho do dr. Alexandre de Castro Correia, ao que nos parece, tem, antes, enderêç̧o didático, visando auxiliar o estudante geralmente pouco aparelhado para apreender, com segurança, diretamente, os vetustos e hoje tão desprezados textos latinos. Nesse aspecto, reputamos de real utilidade o esfôrço do ilustre jurista patrício. Não podemos, contudo, forrar-nes ao dever de acentuar que teria sido de muito maior interêsse ainda que o autor nos houvesse brindado com o resultado de suas observações pessoais sôbre o assunto, de vez que a firmeza e o critério com que soube interpretar o texto das Pandectas revela o estudioso de assuntos romanísticos. Isso, porém, é claro, não desmerece o valor da contribuição apresentada pelo dr. Alexandre Augusto de Castro Correia. Diante disso, não hesita esta Comissão em aplaudir êsse trabalho pela fidelidade de trasladação do texto original, e opinar pela sua inclusão nos Anais do Congresso.

Pôrto Alegre, 17 de agôsto de 1950.

ELPÍDIO FERREIRA PAES - Relator
Pe. AFONSO SCHMIDT 